\title{
Programmed for sex: Nutrition-reproduction relationships from an inter-generational perspective
}

\author{
Richard M Sharpe \\ MRC Centre for Reproductive Health, The Queen's Medical Research Institute, The University of Edinburgh, \\ Edinburgh, UK \\ Correspondence should be addressed to R M Sharpe; Email: r.sharpe@ed.ac.uk
}

\begin{abstract}
Reproduction is our biological reason for being. Our physiology has been shaped via countless millennia of evolution with this one purpose in mind, so that at birth we are 'programmed for sex', although this will not kick-start functionally until puberty. Our development from an early embryo is focused on making us fit to reproduce and is intimately connected to nutrition and energy stores. Fluctuations in food supply has probably been a key evolutionary shaper of the reproductive process, and this review hypothesizes that we have developed rapid, non-genomic adaptive mechanisms to such fluctuations to better fit offspring to their perceived (nutritional) environment, thus giving them a reproductive advantage. There is abundant evidence for this notion from 'fetal programming' studies and from experimental 'inter-generational' studies involving manipulation of parental (especially paternal) diet and then examining metabolic changes in resulting offspring. It is argued that the epigenetic reprogramming of germ cells that occurs during fetal life, after fertilisation and during gametogenesis provides opportunities for sensing of the (nutritional) environment so as to affect adaptive epigenetic changes to alter offspring metabolic function. In this regard, there may be adverse effects of a modern Western diet, perhaps because it is deficient in plant-derived factors that are proven to be capable of altering the epigenome, folate being a prime example; we have evolved in tune with such factors. Therefore, parental and even grandparental diets may have consequences for health of future generations, but how important this might be and the precise epigenetic mechanisms involved are unknown.
\end{abstract}

Reproduction (2018) 155 S1-S16

\section{Introduction}

We live in an age when reproduction is not the force in our lives that it was historically. Not much more than a century ago, average family sizes/birth rates were huge by modern day standards, even if the reasons for this (need children for family support, high child mortality, short life expectancy, poor contraception) may appear rather alien to us in the modern, developed world. Consequently, back in these times, fertility was of central importance in most people's lives, in ways that are far less obvious today. In the Western world, and increasingly in the developing world, our perception now is that reproduction (i.e. fertility) is at our beck and call - we can turn it off and on (in women) when it suits us, a view reinforced by the development of a battery of assisted reproduction techniques for when things are not so straightforward on the fertility front. Therefore, it is easy to see how we have come to consider ourselves as being in control of our reproduction rather than reproduction being in control of us. Such thought processes have unfortunately permeated into biomedical research and have played a role in downgrading the importance of 'reproductive research' and its priority for funding. In this review, I hope to show that our present perspectives are divorced from reality and that, whether we appreciate it or not, reproduction is very much in control of us, and this control permeates almost every aspect of our lives. Conversely, any major changes to our lifestyle and environment, in particular to our diets and metabolism, have the potential to impact reproduction, and perhaps also the future health and wellbeing of our children and grand-children.

Over millennia, evolution has shaped us as we are today with one purpose in mind - to reproduce. It is our biological reason for being. Our DNA is immortal and will persist (through our children), whereas our bodies (i.e. ourselves) are simply short-lived carriers of that DNA - what could be viewed as evolutionary 'pass the DNA parcel' (but with ultimate sequential fatality for the players). As a consequence, all of our development and function are geared towards the purpose of reproduction. Once you accept this premise (and unfortunately not many do) you learn to view our physiology and development through the prism of reproduction. This formed the basis for my 'Sex in three cities' series of talks and for the discussion and hypotheses offered below. 
The aim is to get the reader to think about reproduction as a long-term investment and to consider whether nature has evolved epigenetic regulatory mechanisms to enable rapid adaptation of future offspring to their perceived nutritional environment in order to gain a long-term reproductive advantage.

\section{Sex and reproduction are at the forefront during development}

It is understandable for us to think that, until we hit puberty, sex and reproduction do not matter and play no role in our lives, because from a purely functional perspective this is correct. However, once successful fertilization has occurred and 'reproduction is underway', nature's focus is on sex and reproduction for the new conceptus almost straight away. Thus, soon after implantation of the new embryo and before any recognizable body-plan is in place, the primordial germ cells (=future reproduction) are set aside like 'crown jewels' (Johnson \& Alberio 2015, Canovas et al. 2017) in what can be viewed as the first definitive cell differentiation of the body to occur during development. Moreover, as soon as a body-plan is in place, for what can now be termed a fetus, one of the very first events is to decide on which sex the fetus is to become and to orchestrate the development of a complete reproductive tract and gonad appropriate for the sex of the fetus. In humans, this is more or less completed by around $12-14$ weeks of gestation when the fetus is only $3-5 \mathrm{~cm}$ in length. It is becoming increasingly evident, in males at least, that much of the reproductive dysfunction that becomes apparent in young adulthood may originate because of faulty programming (by androgens) during this early fetal period - the so-called testicular dysgenesis syndrome (TDS). For space reasons, this will not be discussed here, but interested readers can refer to relevant publications for details (Dean \& Sharpe 2013, Skakkebaek et al. 2016, van den Driesche et al. 2017).

In contrast to gonad and reproductive tract differentiation, sexual differentiation of the brain, including the programming of sex-specific reproductive behaviours is programmed later in gestation, probably in the second and third trimester in humans (Swaab 2007). Thus, a functional reproductive system is fully in place by birth in both sexes in humans, although it normally remains dormant until it is activated (by hormones) during puberty; however, such activation can be triggered prematurely at any time after birth, which is termed precocious puberty (Leka-Emiri et al. 2017). In the context of the present article, the point to be made is that a 'reproductive plan' is in place from the earliest points of embryonic and fetal development, hence, the notion that we are 'programmed for sex (i.e. for reproduction)' from the moment we are born. As will be argued throughout the rest of this article, a more sophisticated aspect of this plan might involve adjusting aspects of reproductive and/or physiological (e.g. metabolic) development to the perceived environment (primarily nutrition/food supply) into which it will be born, with the aim of giving the individual a reproductive advantage (Fig. 1). This is not a wild idea, because it is already well established that most key aspects of the reproductive process in both sexes are closely attuned to the environment and to energy supply.

\section{Interplay between energy stores, metabolism and reproduction}

Long-term reproductive success requires that reproductive processes are attuned to the environment, in particular to the food/nutrient supply. It is for this reason that most mammals are seasonal breeders, they reproduce (gametogenesis, sexual behavior/mating) such that it will lead to birth of the resulting offspring at a time of year when food will be abundant (usually the spring). In such animals, photoperiod is the most important cue used to time the seasonal 'switching on and off' of reproductive processes in both sexes (Malpaux et al. 2001, Henningsen et al. 2016). Such cues are used not only to control reproduction but also to control appetite to ensure that, for example, species in which a pregnancy is carried over the winter have accumulated enough fat (energy) stores to support fetal growth (Clarke et al. 2000); similar seasonal changes also occur in males (Lincoln et al. 2001). As well as optimizing reproduction, this close attunement to the environment provides mechanisms via which the species can potentially adapt reproduction to alterations in the food supply. Although humans are not seasonal breeders, we evolved from such a background and there are clear echoes of seasonality in, for example, birth and twinning rates (Rojansky et al. 1992, Cummings 2014, Sharpe 2017) and in sperm counts in men (Jorgensen et al. 2001, Sharpe 2017). Moreover, in general, it is the same processes that regulate normal puberty as regulate seasonal activation of reproductive function in seasonal breeding species; the latter can therefore be considered as 'seasonal puberty' (Smith \& Clarke 2010).

There is now general recognition that timing of reproductive function onset (puberty) is orchestrated by a push-pull system in the hypothalamus involving factors that lead either to suppression or stimulation of $\mathrm{GnRH}$ secretion, which in turn regulates gonadotrophin synthesis and secretion and their effects on growth and function of the gonads (Wahab et al. 2015). The same systems are also used to control seasonal reproduction in seasonally breeding mammals, although there can be species-specific refinements to the precise control mechanisms (Smith \& Clarke 2010, Henningsen et al. 2016). Current thinking (Fig. 2) is that GnlH (gonadotrophin-inhibiting hormone; also termed RFRP-3) 


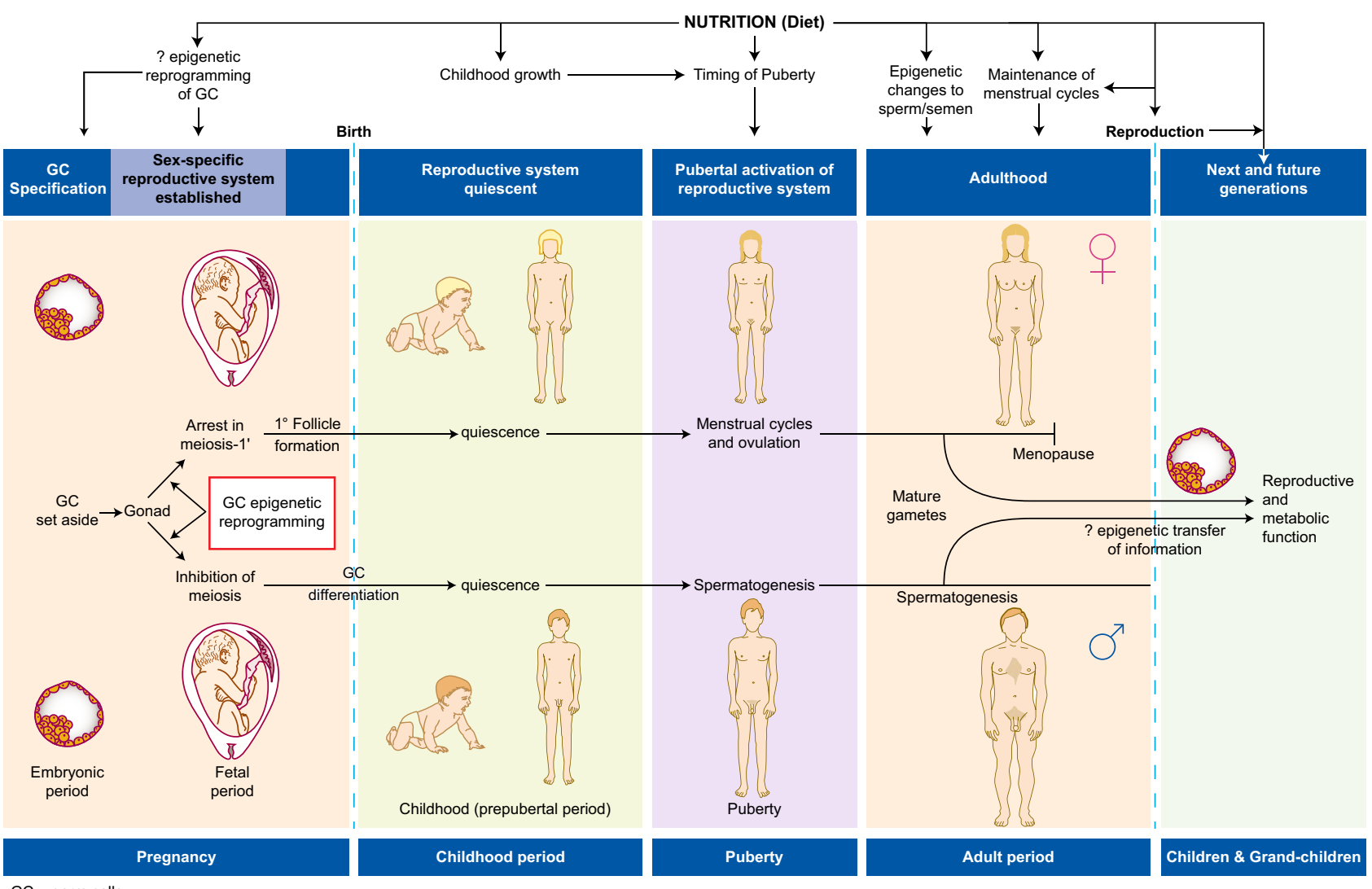

$\mathrm{GC}=$ germ cells

Figure 1 Key steps in reproductive development and function during the life-course and the points at which nutrition can impact this process. The potential epigenetic impacts are discussed in detail in the text.

exerts negative control of GnRH secretion, whereas kisspeptin (KP) exerts positive control (Smith 2012, Wahab et al. 2015), although time may reveal that there are also other modulatory pathways. In parallel to effects on GnRH, GnlH and KP also exert important effects on appetite control, based on a variety of experimental studies (Wahab et al. 2015). Thus, GnlH is oroxigenic (appetite-stimulating), ensuring that further energy stores will be built up whilst reproduction/puberty onset is suppressed, whereas KP is anorexigenic (appetitesuppressing). Although it may seem odd that KP is anorexigenic, it needs to be kept in mind that activation of the KP system is dependent on signals within the body that sufficient energy (fat) stores have been accumulated to support puberty and, in females, pregnancy; thus, further stimulus to increase appetite is no longer needed. Recent evidence also points to a role for KP in promoting sexual and couple-bonding behavior in human males (Comninos et al. 2017), demonstrating how all aspects of the reproductive process are linked mechanistically to nutritional/energy store-modulated factors.

As with animals, it is likely that the driving force behind seasonal influences on human reproduction, from an evolutionary perspective, is fluctuations in food availability, although it has to be recognized that this can exert effects by impacting infant mortality as well as birth rate (Hayward \& Lummaa 2013). However, if reproduction is 'our reason for being', then our reproductive lives should also show other manifestations of the influence of food/nutrition and evidence for our attunement. This can be illustrated by examining the effect of nutrition on timing of the age of menarche (=puberty) in girls, because this is arguably the pivotal event in human reproduction (Fig. 1). To ensure reproductive success, girls need to have acquired certain essential physical features prior to initiation and completion of puberty, namely sufficient stature and skeletal development to support a pregnancy (Villamor \& Jansen 2016). Even when this box is ticked, it is probably nutritional status that finally calls the shots, as it is essential that the female has sufficient energy (fat) stores to support both the pregnancy and the following lactation. If energy stores fall below a certain threshold, such as in women with anorexia, then the reproductive axis is essentially switched off (Kaplowitz 2008). In the human context, sufficient social and emotional development are probably also important for reproductive success, but this is an aspect of considerable complexity (see Gluckman \& Hanson 2006) and will not be considered further here. 


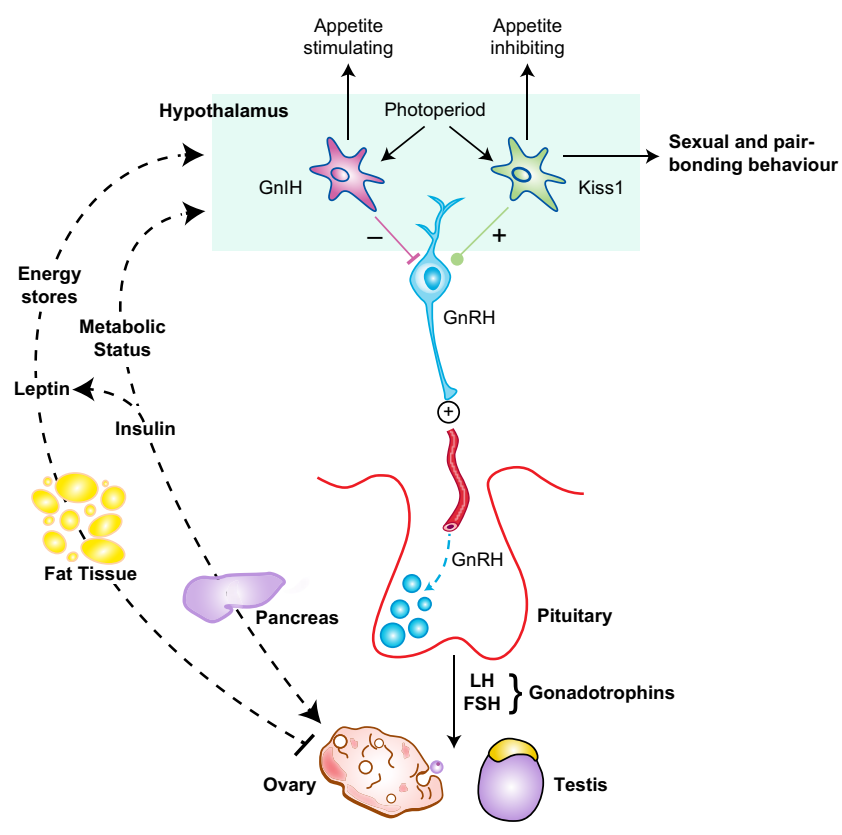

Figure 2 Principal components of the interface between the metabolic system and adipose tissue/energy stores and activation of the reproductive system at puberty. $\mathrm{GnIH}$, gonadotrophin-inhibiting hormone; $\mathrm{GnRH}$, gonadotrophin-releasing hormone; Kiss1, kisspeptin.

Acquisition of sufficient energy stores is important in initiating female puberty for the reasons just outlined. By depositing these fat stores in breast tissue and around the thighs and buttocks in young women, this also acts as a signal to males that the woman has attained reproductive age, and is thus 'fit for reproduction'. The clearest demonstration of this is that when there is no intact leptin signal from fat stores, due to mutations in the leptin gene or its receptor, then puberty fails to occur (Kaplowitz 2008). Moreover, in normal girls, leptin levels are positively associated with age at menarche (Matkovic et al. 1997) and high leptin levels are associated with earlier menarche independent of fat stores (Gavela-Perez et al. 2016). Indeed, improved nutrition has undoubtedly been the key factor in determining the decrease in age at menarche in girls that has occurred since the mid-1800s, although this has stabilized in developed countries since the mid-1900s (Sorensen et al. 2012, Biro \& Kiess 2016).

In contrast to females, the evidence for nutrition and fat stores playing a role in male puberty is less evident, probably because acquisition of adult reproductive function in males is not especially energy demanding, as it is in females. Nevertheless, carefully designed studies have provided some evidence for recent advance in the age of puberty in boys, associated with nutritional status/BMI, although the changes involved appear more modest than those that have occurred in girls (Sorensen et al. 2010, Biro \& Kiess 2016). An interesting issue that such sex differences raise is whether, historically, age of puberty was comparable in girls and boys and has become increasingly disparate since the 19th century. However, as puberty timing in boys is far harder to define than in girls, accurate historical data is not easily available.

From the brief outline above, it is clear that nutrition plays a key role in the reproductive process whether in seasonal or non-seasonal breeders (e.g. humans). It seems obvious why this should be the case in females, especially for puberty timing, because pregnancy and the following lactation are critically dependent on adequate nutrition and energy supplies, and a firm foundation for successful reproduction is essential - and thus the fulfillment of nature's plan. However, it is equally evident that the same seasonal/environmental cues that drive appetite and energy intake in females also do the same in males (Lincoln et al. 2001, Anukulkitch et al. 2007), perhaps because breeding and associated spermatogenesis may also be energy-demanding, albeit on a different scale to the female. The important take-home message is that both sexes are in tune with their environment and responsive to changes in appetite, which is in turn attuned to the food supply (Fig. 1). This being the case, it is not a huge leap of the imagination to consider that such attunement could influence more than the timing of puberty/seasonal breeding. Given the importance of successful reproduction in the long-term survival of any species, and the fact that reproduction is by definition 'inter-generational', might attunement of reproduction to food supply/nutrition also operate in an inter-generational context? I attempt to make a case for this in the rest of this article.

\section{Reproduction and natural selection}

We are all familiar with this concept, which originated with Darwin as 'survival of the fittest' and was then modified into the concept of natural selection. Sexual reproduction plays the deciding role in this process in two fundamental ways. First, natural selection presumes that only the fittest will survive to reproduce or will reproduce the most, hence providing the basic pivot for the whole process. Second, because of the recombination events during the processes of gametogenesis and then fertilization, reproduction provides the literal breeding ground for new genomes that may prove to be better adapted to any change in the environment or to a new environment or niche. One can see how this could work over huge spans of time, but it seems far too risky if the requirement is to enable adaptability of a species to a rapid environmental change such as food availability. Indeed, it amounts to little more than a random throw of the genomic dice which, circumstantially, might turn out to be an advantage or a disadvantage to survival of that individual if its environment changed.

When viewed through the reproductive prism, it seems odd that the huge investment that has been made over millennia in attuning of reproduction to the environment in a given species, could be based on literal 
'reproductive roulette' via a throw of the genomic dice. Frankly, this seems unfit for purpose, which convinces me that nature would have evolved far better ways of adapting (quickly) without having to change the DNA itself - by using epigenetic mechanisms. Against this view is the undisputed fact that numerous species have become extinct over time, usually in the face of dramatic environmental change, so why did they not adapt epigenetically? Of course, there are limits to adaptability of any species - dinosaurs could not have adapted to the calamitous change in their environment that wiped them out. But adaptation to much more common, but less dramatic changes, for example, in seasonal food supply, would make survival and evolutionary sense. Moreover, such adaptive changes would be most effective if they were fast (i.e. not requiring multiple generations to be effective) and flexible (e.g. easily reversible), features that are simply not compatible with natural selection based on changes in DNA sequence. In contrast, epigenetic changes within germ cells can theoretically offer such possibilities, and the evidence that such mechanisms might be operative is discussed below.

\section{Epigenetic adaptation and reproduction}

From a purely theoretical point of view, there are several distinct periods during the reproductive process when epigenetic adaptive changes could be induced to better fit resulting offspring to a changed environment (Box 1); here, we will simply focus on evidence related to changes in nutrition/food supply, but in theory, adaptive changes to other environmental factors such as stress (Bale 2014) could also be important. First, the developing or maturing gametes could be affected by nutrition of the individual. Second, the zygote/early embryo could be affected, primarily by nutrition of the mother but perhaps also by the father's nutrition. Third, the developing fetus could be affected, primarily by maternal nutrition. Fourth, the resulting offspring could be affected by nutrition at one or more points during the life course - this will not be considered here. There is a substantial body of experimental evidence for effects during the first three of these periods, which are summarised below. However, before dealing with this evidence, it is appropriate to first comment on several major issues to be kept in mind when considering and interpreting this evidence. These relate to the nature of the evidence, whether 'effects' have been induced via maternal or paternal 'exposures', and the mechanism for such effects; in many ways, these three aspects are inter-related.

The first point is that the majority of the evidence for adaptive changes in offspring with a presumptive epigenetic basis is indirect - it is based on changes in obesity and/or metabolic pathways or disease susceptibility in the offspring without evidence that this is the direct effect of a nutritionally induced epigenetic change at some point during the origin/development
Box 1 Opportunities for induction of specific epigenomic changes in response to the nutritional environment (or diet).

- During gametogenesis - especially during spermiogenesis in males

- During epigenetic reprogramming of primordial/fetal germ cells

- During genome-wide reprogramming post fertilisation (in pre-implantation embryos)

- During fetal development (e.g. organogenesis)

of these individuals. Therefore, an epigenetic adaptive change has been presumed rather than demonstrated, and in some cases, alternative explanations may not have been considered or excluded. The second point is whether the presumptive adaptive change has been induced as a consequence of an experimental change in nutrition of the mother or father. If the mother's nutrition was changed does this lead to changes in the offspring via an altered uterine environment that, for example impacts placental function, or because of an epigenetic change in the offspring? This issue is especially important when considering the inter-generational transmission of 'effects', as discussed further below. It is more likely that a change in the offspring has an epigenetic basis if it results from a specific dietary change in the father, because there is no potential confounding of the uterine environment involved. However, it is still possible with paternally mediated effects that alternative pathways could be involved, for example, via transmission of factors (e.g. miRNAs) via seminal plasma that then impact early embryo development without any direct transfer of epigenetic changes via the sperm chromatin itself (Daxinger \& Whitelaw 2012, Binder et al. 2015). Of course, this example still ultimately involves an epigenetic mechanism, but not one involving the sperm epigenome itself. Finally, the third point is that in nearly every experiment in which a presumptive epigenetically mediated transmission of a phenotypic change to offspring has been transmitted, the actual epigenetic mechanism has not been elucidated.

The brief outline of the above 3 points reminds us that, unlike with DNA-mediated inheritance, epigenetically mediated inheritance is far more complex to unravel, pin down and study. Although this is due in part to our present ignorance about epigenetic regulatory mechanisms, it is also an inherent feature of epigenetics. An epigenetic change can be ephemeral, it may cause its effect in the offspring and then disappear, leaving only the downstream consequences of the initial effect visible; at least with DNA mutations/polymorphisms, the causal evidence always remains. As a consequence, most of the studies involving putative inter-generational epigenetic effects after experimental intervention, are based on demonstrating phenotypic changes in the offspring, compared with relevant controls. 


\section{Offspring effects resulting from dietary changes during parental gametogenesis}

There are numerous studies which have shown that experimental manipulation of the diet in rodents during puberty/adulthood can impact the next generation (Wei et al. 2015). Most studies have focused on the impact of parental obesity and/or a high-fat diet (HFD), and in general, these show that this results in increased risk of obesity, metabolic dysfunction and pre-diabetic changes in the offspring, although in some studies only male offspring are affected. The majority of studies have focused on paternal obesity/ HFD (Box 2) because this avoids any confounding 'uterine effects' that are possible with maternal exposures and have shown adverse metabolic and reproductive changes in offspring of such fathers $(\mathrm{Ng}$ et al. 2010, Palmer et al. 2011, Fullston et al. 2013, McPherson et al. 2014); some studies have shown that such 'programmed' effects are transmissible to further generations (Fullston et al. 2012, King et al. 2013). These paternally transmitted effects are not just triggered by 'over-nutrition' because feeding males on a low protein diet prior to mating, also results in altered hepatic expression of a range of genes involved in lipid and cholesterol metabolism in offspring sired by such males (Carone et al. 2010). One of the more interesting findings is that the next-generation effects of paternal obesity in mice can be reversed by altering the diet of the fathers or by getting them to increase their exercise levels (Palmer et al. 2011, McPherson et al. 2014, Barres \& Zierath 2016). A study of obese men before and after bariatric surgery provides support for this (Donkin et al. 2015). These authors showed, first, that sperm from lean and obese men showed differences in DNA methylation and in small non-coding RNAs, and second, that obese men who underwent bariatric surgery showed dramatic remodelling of sperm DNA methylation, notably at genetic locations implicated in central control of appetite.

\section{Box 2 Evidence that a modern Western diet in fathers can 'reprogram' future offspring.}

- Experimental rodent dietary intervention studies

- cause epigenetic changes to sperm

- result in metabolic changes in offspring

- these effects are dynamic and reversible

- During histone replacement in spermiogenesis, specific regions containing key development/metabolic genes retain nucleosomes

- Numerous plant-derived products in a balanced diet have the potential to modulate the epigenome

- A Western style diet may be deficient or unbalanced in these 'epigenetic modulators' (e.g. folate)
A key, presently unanswered question, is whether the experimental dietary studies in adult male mice can be translated to human males. Human cohort studies have been used to try and assess relationships between parental obesity/BMI and offspring BMI, but the results obtained have been quite mixed. Two studies have reported a significant association between paternal and offspring BMI (Birbilis et al. 2013, Linabery et al. 2013), and both studies also showed a significant association between maternal $\mathrm{BMI}$ and offspring BMI, although the studies differed as to which parent's BMI had the strongest association with offspring BMI. A systematic review, which only identified three suitable cohort studies with full data, found that no strong conclusions could be reached based on present data (Patro et al. 2013). Whether this means that inter-generational effects of obesity are less evident in humans than in experimental rodent studies or whether the large number of potential confounding factors in human studies, especially with maternally mediated 'effects', creates too much noise for inter-generational effects to be discernible, is a matter for debate and further investigation. In this regard, one interesting study, which is discussed in detail later in this review, has shown that variation in methylation of the pro-opiomelanocortin (POMC) gene in neurons involved in appetite control is strongly correlated with BMI in individual humans (Kuhnen et al. 2016). This is significant because methylation of this gene is determined embryonically and can be affected by peri-conceptual diet of the mother as well as by epigenetic transmission from the father (Kuhnen et al. 2016).

The aforementioned mouse and human studies indicate that whatever the epigenetic mechanism underlying the inter-generational effects of paternal obesity, they are dynamic and can adapt to alterations in the father's nutritional environment (Box 2). However, the big unanswered question is what is the epigenetic mechanism for these dynamic inter-generational effects? The honest answer is that, at present, there is a lack of examples to show that a diet-induced specific epigenetic change(s) in germ cells in one generation is demonstrably transmitted to, and responsible for, an observed consequence in the next generation(s); logistically, such studies are extremely challenging. Nevertheless, there are a growing number of studies that show how paternal diet can cause epigenetic changes in sperm, for example, via altering the miRNA profile (Fullston et al. 2013, Grandjean et al. 2015, Sharma et al. 2016), chromatin structure/histone modifications (Carone et al. 2010, Ost et al. 2014) or the DNA methylome (Radford et al. 2014) of spermatozoa (Box 2). However, when in spermatogenesis such effects are induced, and whether these germline epigenetic modifications are directly responsible for phenotypic changes in offspring are unknown. 


\section{Offspring effects resulting from maternal dietary changes during embryogenesis}

There is abundant experimental evidence from mouse and sheep studies that show that altered maternal nutrition during the peri-conceptual pre-implantation period can result in adverse metabolic function/ pre-diabetic changes as well as size, obesity, altered blood pressure, behaviour and adrenal function in the resulting offspring in later life (Grace \& Sinclair 2009, Fleming et al. 2012, 2015; Box 1). Most of these studies have focused on maternal protein under-nutrition, but it also appears that over-nutrition/obesity may cause similar effects (Fleming et al. 2012). As indicated earlier, studies in pregnancy are subject to potential confounding from uterine environment effects, but the mouse studies have sidestepped this problem by flushing the embryos from mothers that had been exposed to a low protein diet just during the peri-conceptual period, and then implanting them into the uterus of mothers fed a normal control diet. When these resulting offspring grew up they exhibited comparable dysfunction to offspring that had continued development in the uterus of mothers who had been exposed peri-conceptually to a low protein diet (Watkins et al. 2008). It appears that one early response to exposure of the mouse embryo to a low protein diet is to cause increased proliferation of the trophectoderm and its outgrowths during implantation (Eckert et al. 2012) as well as functional changes to nutrient transport mechanisms (Watkins et al. 2008, Fleming et al. 2015). Another study has shown that a maternal low protein diet just around the time of conception results, in offspring, in excessive ribosomal DNA ( $\mathrm{rDNA}$ ) transcription and ribosome biogenesis when nutrition after birth is plentiful (Denisenko et al. 2016), providing a plausible mechanism to explain increased risk of obesity ('overgrowth') in such individuals. Indeed, the authors suggest that $r D N A$ is a plausible candidate for a 'thrifty gene involved in nutrient ulitization control, which is tuned by nutrient availability in utero'. Adaptive changes such as these are considered to sow the seeds for metabolic and other dysfunctions in adulthood (Fleming et al. 2015, Xu \& Sinclair 2015).

The precise epigenetic mechanisms that underlie the various phenotypic changes in offspring affected as a result of maternal peri-conceptual diet remain to be determined, but studies of mouse embryoid bodies derived from cell lines from blastocysts from mothers exposed to normal or low protein diets periconceptually, show diet-dependent histone changes that are propagated during cell divisions, which may be involved (Sun et al. 2015). Studies focussed on the $r D N A$ gene and how its expression may be altered by peri-conceptual diet of the mother, could be particularly informative as results already point to altered gene methylation as being important (Denisenko et al. 2016). In this regard, it is already apparent that 1-carbon metabolism, which plays an essential role in DNA methylation may be an important pathway of effect for peri-conceptual changes in diet etc. (Xu \& Sinclair 2015), as is discussed in more detail below.

One particularly important implication of the experimental mouse and sheep embryo studies is in regard to assisted reproduction techniques (ART) in humans, as these routinely require short-term culture of early conceptuses. If the animal studies are any guide, differences in the 'nutrients' in the culture medium employed (e.g. folic acid) could potentially induce epigenetic changes that alter later development and function of the embryo and/or placenta, and whatever downstream health consequences these might trigger (Grace \& Sinclair 2009, Steegers-Theunissen et al. 2013). There is growing evidence for such effects in humans (Steegers-Theunissen et al. 2013, Sunde et al. 2016), and this area is likely to attract increasing attention as our understanding of the vulnerable or adaptive epigenetic mechanisms in the early embryo are identified.

\section{Offspring effects resulting from maternal dietary changes during the fetal period}

The term 'fetal programming' has been used extensively as a catch-all for describing the adverse health consequences that result from fetal growth restriction, whether this be due to impaired placental development and/or function, to maternal under-nutrition or to maternal over-nutrition or HFD, which can adversely impact placental function (Huypens et al. 2016, Musial et al. 2017). This leads to increased risk of obesity and metabolic syndrome disorders when the growthrestricted fetus becomes an adult; such effects have been extensively described in humans, domestic and laboratory animals (Desai et al. 2015, Reynolds et al. 2015, Aiken et al. 2016a, Cheong et al. 2016) and will only be outlined in general here. One interpretation of such findings is that, irrespective of the reason for fetal growth restriction, it is perceived by the fetus as evidence of a poor nutritional environment in the world into which it will be born, which triggers metabolic changes to better adapt it to this environment - the so-called 'thrifty phenotype' hypothesis (Hales \& Barker 2012). However, when such growth-restricted fetuses are born into a world of normal nutrition or, increasingly, one of over-nutrition (Western diet), their inappropriate metabolic reprogramming leads to over-compensation of growth (especially in the immediate postnatal period) and consequential increased risk of obesity, metabolic dysfunction/type II diabetes and all of the downstream adverse health changes that these changes bring, including cardiovascular disease (Alexander et al. 2015). These (mal)adaptive metabolic changes must have an epigenetic basis, and various such changes have been described in different such models (Vickers et al. 2011, 
Desai et al. 2015, Banik et al. 2017). Of interest is that the maladaptive changes can include reprogramming of central appetite regulation (Martin-Gronet et al. 2016), pancreatic $\beta$-cell mass (Portha et al. 2011), liver metabolic function and adipose tissue effects (McMillen et al. 2008, Vickers et al. 2011), demonstrating that the effects are very much a 'cover-all' for modulation of food intake, energy metabolism and storage, rather than being targeted to a single aspect.

From the reproductive perspective, the adverse health effects of nutrition-induced fetal reprogramming means that the individual is less fit to reproduce in general terms. However, there may also be more specific effects. For example, it has been shown in rodent models that feeding the mother a low protein diet or a Western style obesogenic (high fat/high sugar) diet during pregnancy, both result in reduced ovarian reserves in female offspring (Aiken et al. 2015, 2016b). Interestingly, other rodent studies have shown that similar effects are induced by maternal exposure to analgesics during pregnancy (Dean et al. 2016, Holm et al. 2016), probably involving a prostaglandin E2-mediated pathway (Dean et al. 2016). If similar effects of maternal diet or analgesic exposure occur in human pregnancy, it could have significant impact on female reproductive lifespan, but designing relevant studies in humans is extremely difficult because of their complexity and duration (Aiken et al. 2016a).

\section{Intergenerational effects: relationship to fetal germ cell reprogramming}

In rodents, fetal primordial germ cells go through a process of widespread genomic demethylation during and following their migration into the genital ridge/ gonad, followed some days later by remethylation in a sex-dependent manner (earlier in males than in females, where it occurs postnatally) (Sasaki \& Matsui 2008, Seisenberger et al. 2012, Kobayashi et al. 2013) (Fig. 1, Box 1). At the same time, dynamic changes in histone methylation and in other histone modifications also occur (Seki et al. 2007, Sasaki \& Matsui 2008, Prokopuk et al. 2017). This reprogramming process is thought to be essential for later sex-specific germ cell development, including pluripotency changes and entry to meiosis (Reik 2007, Sasaki \& Matsui 2008, Seisenberger et al. 2012, Guo et al. 2017). The more limited evidence available for the human fetus demonstrates that similar DNA methylation and histone changes also occur (Biermann \& Steger 2007, Wermann et al. 2010, Tang et al. 2015a,b, Guo et al. 2017), these changes taking place during weeks 5-7 of gestation (Tang et al. 2015a,b); however, there may be some differences between mouse and human as to how these reprogramming changes are affected (Tang et al. 2015a,b, 2016, Guo et al. 2017). Viewed through the reproductive prism, the fetal germ cell epigenetic reprogramming also presents an opportunity for sensing of environmental cues to dictate the pattern of, for example, remethylation, such that specific functions of the F1 offspring generated from these germ cells are adapted to the perceived environment (Stringer et al. 2013). Neat though this idea may be, there are two big potential barriers to its feasibility. First, when sperm are generated, major changes to chromatin architecture (histone replacement by protamines) and DNA methylation occur, such that epigenomic changes originating from fetal life are likely to be erased (Biermann \& Steger 2007, Sasaki \& Matsui 2008). Second, and more importantly, during fertilization, the zygote undergoes genome-wide epigenetic reprogramming to allow reacquisition of totipotency (Reik 2007, Stringer et al. 2013). Therefore, if environmentally influenced epigenetic changes to fetal germ cells in males are to persist so as to change the function of the resulting postnatal individual, they have to be resistant to the reprogramming changes during spermiogenesis and after fertilization (Box 1). There is convincing evidence that this can occur under experimental conditions and growing insight as to the mechanisms involved.

The most informative evidence comes from two studies published in Science (Radford et al. 2014, Siklenka et al. 2015), which show, respectively, how experimentally induced changes to either DNA or histone methylation during fetal germ cell development leads to changes in sperm that are transmitted inter-generationally and are associated with altered phenotype in the offspring (Box 2). In the first study (Radford et al. 2014), pregnant mice were subjected to a $50 \%$ restricted calorie diet only during the period of germ cell epigenetic remethylation in the male fetus (e12.5-e18.5). When male fetuses from these underfed mothers grew to adulthood, their sperm exhibited locus-specific DNA hypomethylation, these changes being restricted to nucleosome-retaining regions of the DNA (i.e. regions where histones had not been replaced by protamines). These regions are not random, but contain developmentally important genes (Box 2) - imprinted gene clusters, HOX gene clusters, promoters of developmental transcription and signaling factors (Hammoud et al. 2009) and appear to be conserved in mouse and men (Brykczynska et al. 2010, Erkek et al. 2012). Much of these regions are also resistant to DNA methylation reprogramming in the early embryo and may thus allow persistence of any methylation changes for long enough to affect the phenotypic development of the next (F2) generation. It is intriguing that several of the genes affected by hypomethylation in the study by Radford et al. (2014) have known roles in glucose tolerance and metabolism as well as in type 2 diabetes (Box 2), which fits with the notion of fetal adaptive reprogramming to nutritional changes, as well as with other experimental studies described earlier. However, Radford et al. (2014) also showed that the differential methylation changes in F1 sperm were not maintained in F2 tissues, but instead, 
the latter showed altered expression of genes located close to the genomic regions that had been originally hypomethylated. The authors suggest this may indicate 'sustained alterations in chromatin architecture, transcriptional regulator networks and/or cell type or tissue structure' as a direct consequence of the original epigenetic changes in sperm.

If the example of Radford et al. (2014) is illustrative, it suggests that intergenerational epigenetic changes in male germ cells can persist for only one generation, but this may still result in phenotypic changes in the following generation. Whether the latter would then affect the next generation (F3) via male germline transmission, as some have argued does occur (Anway et al. 2005), is dependent on there being de novo changes to sperm of the F2 animals which are themselves transmissible, a mechanism for which is unclear (Szyf 2015). A detailed study that tried to reproduce the results of Anway et al. (2005) demonstrated instead that whilst treatmentinduced DNA methylation changes were detectable in pro-spermatogonia of F1 males (that had been directly treatment-exposed in utero), no such changes were detectable in pro-spermatogonia of F2 males that had been sired by treatment-exposed F1 males (Iqbal et al. 2015). In this regard, this study is very much in keeping with the findings of Radford et al. (2014). In a more general sense, other findings that have shown phenotypic changes in F2 offspring that are different from those found in the F1 who were exposed in utero to an experimental treatment, might also be considered as fitting with this paradigm (Dean et al. 2016).

Another aspect to the studies of Radford et al. (2014) is that, during demethylation of primordial germ cells in mice, some areas, termed variably erased $\mathrm{CpG}$ islands (CGIs) (VECs; Seisenberger et al. 2012) remain methylated at all stages, including in mature oocytes and sperm (Box 2); intriguingly, this can include CGls in genes involved in insulin-stimulated glucose transport that are associated with type 2 diabetes. More of these methylated CGls are found in sperm than in oocytes, suggesting that more VECs escape 'methylation reprogramming' in male primordial germ cells (Box 1 ). These CGls could also be environmentally sensitive and provide another pathway for intergenerational epigenetic inheritance in mammals (Seisenberger et al. 2012). In human PGCs, it has also been shown that specific regions of the genome escape 'genome-wide demethylation', and these include areas that are of known importance in neural development/brain disorders and obesity and, intriguingly, these 'demethylation escapees' showed variable methylation levels between PGCs from individual fetuses (Tang et al. 2015a,b, 2016). These regions provide the means for differential transmission of epigenetic memory intergenerationally. Whilst a detailed analysis and comparison of 'demethylation escapee' regions in mouse and human (Tang et al. $2015 a, b)$ revealed considerable differences (i.e. poor conservation), this also identified genes such as the androgen-responsive cell cycle regulatory gene TACC2, which showed resistance to promoter demethylation in human PGCs as was also reported in the homologous gene Tacc2 in mice from the studies of Radford et al. (2014) detailed above, although the actual promoter regions affected differed between mouse and human.

During fetal germ cell de- and re-methylation (Box 1), dramatic changes to chromatin structure involving histone methylation also occur, and these vary considerably between the sexes with much more dramatic increases in histone methylation in male germ cells (Abe et al. 2011). The latter authors suggest that these histone changes may provide a framework for gene methylation changes during differentiation of pro-spermatogonia. More generally, it is agreed that histone methylation changes in fetal germ cells is targeted to developmentally important genes, so-called 'bivalent genes,' involved in later cell specification and differentiation (Lesch et al. 2013, Voigt et al. 2013).

The fundamental importance of correct histone methylation to normal development comes from the second informative study noted earlier (Siklenka et al. 2015), which shows that transmissible epigenetic changes in germ cells can be induced without altering DNA methylation, as in Radford et al. (2014). The authors used transgenesis to induce a human KDM1 A histone lysine 4 demethylase in germ cells in mice and showed that this induced major changes in both coding and non-coding RNA expression in sperm without altering sperm nucleosome structure or DNA methylation. When such animals were mated, they found numerous developmental abnormalities in offspring, and when these offspring were themselves bred, increased incidence of developmental abnormalities were found even out to the F4 generation (Siklenka et al. 2015). The intergenerational transmission of the 'effects' occurred in the absence of transmission of the inserted transgene, and thus, was epigenetic, and could be due either to transmission of different RNA profiles in the sperm or more directly to the changes in histone methylation induced originally by the KDM1A transgene. The authors argue that it is highly unlikely that RNA transmission explains the effects and emphasize that their study shows how paternal exposure to an exogenous factor that alters histones, and thus, chromatin architecture, may have consequences for future generations (Siklenka et al. 2015). Such changes can presumably be induced during any of the phases in which histone and other chromatin changes occur physiologically, whether during fetal life or during gametogenesis in adulthood.

\section{The impact of diet on the epigenome}

The discussion above highlights that during the normal reproductive life-course, there are specific events that potentially allow environmental nutritional factors to 
influence the epigenome (Fig. 1). Additionally, there is growing evidence from experimental animal studies to show that extremes of diet in parents, whether under- or over-nutrition, can cause changes to the epigenome of germ cells, embryo or fetus, which are associated with altered function and health of the affected individual/ offspring, although evidence is mostly lacking for a specific epigenetic cause and effect relationship (Sinclair et al. 2010). Even if we accept that human obesity, which is common, can induce similar epigenetic and health consequences as in the experimental animal studies, the key unanswered question is whether it is specific factors (or their lack) in the diet of obese people/animals that causes the epigenetic changes or whether it is the altered metabolic status of the obese individual that is the cause or is it both? Probably many of us will have been told by our mothers when a child that 'you are what you eat', which translated into a scientifically more accurate description is that a balanced, varied diet is widely considered as being the most healthy, as opposed to a fast-food Western diet that is over-rich in calories and deficient in fruit and green vegetables - and of course, it is the latter diet that is associated with obesity. A wide range of compounds derived from plants are capable of altering DNA methylation or causing histone changes (Box 2), albeit mainly in a cancer setting (Shankar et al. 2016, Tran et al. 2017, Zam \& Khadour 2017). The names of some of these compounds will be familiar to us (e.g. circumin, lycopene, quercitin, resveratrol, genistein), but they are mainly classed as phytochemicals and antioxidants and are present in a range of fruit and green vegetables (Shankar et al. 2016). It is beyond the scope of this article to consider the epigenetic regulatory properties of these compounds, but it is emphasized that (a) exposure to such compounds would have been common in our evolutionary past and (b) our exposure in the modern world will vary considerably depending on whether we eat a balanced diet or an unbalanced/ Western/fast-food diet (Box 2).

One interesting hypothesis, arising from the foregoing discussion, is that because we have evolved whilst eating a plant-rich diet our epigenome is attuned to this because of constant exposure to the phytochemicals in the plants; what a Western diet has done is to disrupt this harmony, possibly with knock-on heritable epigenetic consequences for our children (Krautkramer et al. 2016). It may also mean that it is not the contents of a Western diet that does 'epigenetic harm', rather it is what is missing from the diet. Folate, which is a B-vitamin, is an interesting example in this regard, as it is a vital dietary component that we derive naturally from plants and fruits and which can therefore be deficient in a modern Western diet (Steegers-Theunissen et al. 2013), especially as it is destroyed by cooking and its circulating levels in pregnant women may be reduced by obesity (Maffoni et al. 2017) or by lifestyle factors such as smoking and alcohol consumption (Steegers-Theunissen et al. 2013,
Drake et al. 2015). Folate deficiency, and its relationship to risk of neural tube defects (NTDs) such as spina bifida, has resulted in many countries supplementing common foods (e.g. flour) with a form of folate, folic acid (Gueant et al. 2013), which is resistant to cooking. This supplementation has resulted in major reductions in incidence of NTDs, in some cases by $80-90 \%$ (Czeizel et al. 2011), a change that has also complicated studies into dietary/lifestyle impacts on folate deficiency. Folate/ folic acid metabolites play essential roles in so-called 1 -carbon metabolism, which underpins the process of DNA methylation (Steegers-Theunissen et al. 2013), and these roles and the established relationship between folate deficiency and incidence of NTDs has raised awareness that folate deficiency might have wider 'fetal programming' consequences (Steegers-Theunissen et al. 2013, Xu \& Sinclair 2015, Joubert et al. 2016). This includes possible intergenerational effects as a result of epigenetic changes to germ cells that may result from folate deficiency or from folic acid supplementation (Gueant et al. 2013). Indeed, folate is an essential requirement for many of the stages of reproduction in both sexes, and dietary fluctuations in folate could therefore potentially impact the reproductive process at multiple steps (Ebisch et al. 2007) (Fig. 1). Several studies have addressed this via experimental dietary manipulations in mice or by studies involving folic acid supplementation in human subjects, such as infertile men.

A double-blind placebo-controlled trial of folic acid supplementation \pm zinc sulphate for 6 months in fertile or idiopathic infertile men reported a significant increase in sperm count in the infertile, but not the fertile, group when supplemented with folic acid + zinc sulphate, but no effects with either supplement alone (Wong et al. 2002). Whilst there is some further supporting evidence for such effects (Ebisch et al. 2007), it is noteworthy that another similar study of men with idiopathic infertility found no effect of 6 month's folic acid supplementation on sperm counts (Aarabi et al. 2015), a difference which the latter authors suggested might be due to their infertile group being normospermic, whereas those in the Wong et al. (2002) study were oligozoospermic. Experimental studies in mice, comparing a normal diet vs folic acid-deficient and folic acid-supplemented diets suggest that developmental exposure to a folic acid-deficient diet may result in lower sperm counts in adulthood (Swayne et al. 2012, Ly et al. 2017), an effect that may stem specifically from deficiency during the post-weaning period (Swayne et al. 2012). However, supplementation with a very high level of folic acid (20-fold control levels) during development (mating, pregnancy, lactation and post-weaning) resulted in an even bigger decrease in sperm counts in adulthood than did folic acid deficiency, although a 10-fold supplementary dose had no effect (Ly et al. 2017). Arguably, the most interesting evidence to emerge from mouse experimental studies is that manipulation of folic 
acid levels in the diet throughout development of the male is associated with highly significant changes in DNA methylation in sperm in adulthood, whether in imprinted genes (Ly et al. 2017) or genes implicated in the development of chronic diseases such as cancer, diabetes and autistic-spectrum disorders (Lambrot et al. 2013). Moreover, there is increased incidence of birth defects in the offspring fathered by males that were exposed to a folic acid-deficient diet during their fetal and postnatal development (Lambrot et al. 2013). Now that folic acid supplementation of various common foods is common, it is relatively unlikely that reproductive effects resulting from its deficiency will occur in humans in the developed world. However, it serves as an illustrative example of how gross dietary changes, such as has occurred with a Western style diet, can have farreaching consequences via the reproductive process, as a result of a change in a specific component of the diet - in this case, the reduced level of folate. An important issue to be resolved in future studies is whether the absence/reduction in other specific factors in a modern Western diet might have comparable intergenerational effects to those evident for folic acid/folate (Box 2).

Although it is interesting to imagine how our diets might impact numerous aspects of our physiology and metabolism via epigenetic mechanisms, the burning question is how important are such effects from a health/ disease-risk perspective? It is one thing to show that extremes of parental nutrition, such as famine/starvation in humans or experimental low protein diet in animals, are associated with offspring health changes, but these do not resemble the 'normal' situation in the developed or developing world. However, a small number of studies have begun to address this issue in humans and have generated positive supporting evidence.

A series of studies in rural Gambia (Dominguez-Salas et al. 2013, 2014) have been undertaken to evaluate the influence of normal seasonal changes in diet during the rainy season (='hungry' season) and the dry season (= 'harvest' season) on the blood levels of 13 biomarkers of key components of the 1-carbon metabolism cycle (e.g. choline, betaine, folate, methionine, vitamins B-6 and B-12) in women around the time that they became pregnant. These showed consistent changes in bioavailability of 8 out of 13 factors according to the season of conception in the studied women, leading the authors to conclude that 'naturally occurring seasonal variations in food consumption patterns have a profound effect on methyl-donor biomarkers status' (DominguezSalas et al. 2013). What makes the studies ingenious is that they then studied the DNA methylation status at six established metastable epialleles (MEs) in peripheral blood lymphocytes and hair follicles from the offspring resulting from these pregnancies (Dominguez-Salas et al. 2014). This showed, first, that ME methylation status was highly correlated $(r=0.72 ; n=167)$ in peripheral blood lymphocytes and hair follicles from the offspring and varied in a consistent manner for all MEs according to the season of conception. Moreover, levels of several of the measured biomarkers at the time of conception predicted the mean ME methylation with the direction of effect being consistent with the biological relationship between the biomarkers in question and DNA methylation. It is emphasized that the effect sizes in mean \% DNA methylation for a given ME in offspring conceived in the different seasons were not large, but the significance is that such changes occurred under conditions that are normal, as opposed to extreme (e.g. famine). Importantly, such conditions are likely to have been a common feature of our evolutionary past, so in many respects, these Gambian studies provide strong support for the underlying central hypothesis of the present review.

One of the MEs identified in the Gambian studies as being variably methylated according to season of conception was the tumour suppressor gene VTRNA21 , which plays a role in innate immunity amongst other functions (Silver et al. 2015). This gene was identified independently as a metastable epiallele in a screening study for variably methylated genes, and its methylation status shown to vary between normal Caucasian and Asian adults similar to that shown in the Gambian individuals (Silver et al. 2015). Whether such variation in specific gene methylation results in increased risk of disease was not established in the aforementioned studies, but evidence from another study of methylation in a variably methylated region (VMR) of the proopiomelanocortin (POMC) gene provides support for this possibility (Kuhnen et al. 2016). POMC-VMR methylation status in brain neurons involved in appetite control was found to be strongly associated with individual BMI in different ethnic cohorts, including in individuals from the Gambian studies described earlier. Using the latter, authors showed that POMC-VMR methylation status was partly inherited from fathers, but not from mothers, but its methylation was strongly affected by season of conception similar to the other epialleles described earlier (Dominguez-Salas et al. 2013, 2014, Kuhnen et al. 2016). Thus, maternal diet at conception can modify inherited DNA methylation status, at least for the POMC gene, illustrating the adaptability of the overall process in humans in real-world contexts.

Plant-derived vitamins and phytochemicals are only one aspect of diet, and do not provide essential protein, fats and carbohydrates, raising the question of whether these can also affect the epigenome. This is more complex and less well studied, but there is growing evidence from a variety of sources that histone modifications such as acetylation and methylation can be influenced by dietary carbohydrates (Krautkramer et al. 2016) possibly via interactive effects with the gut microbiome (Liu et al. 2016). The underlying pathways of effect are not so well studied, but an obvious possibility is that dietary factors target the activity of the enzymes that regulate histone 
modifications. For example EZH2, which is responsible for the repressive histone methylation H3K27me3, can be affected by types of fats in the diet (Rodriguez-Miguel et al. 2015), by omega-3 polyunsaturated fatty acids (Dimri et al. 2010), low dietary protein intake (Fontana et al. 2013), by isoflavones (Kanwal et al. 2016) or by sulforafane (Fisher et al. 2016), which is a phytochemical derived from broccoli and brussels sprouts with known tumour-suppressing properties. It is a huge jump from experimental studies such as those above to considering whether variation in maternal diet in human pregnancy can influence the pattern and extent of DNA or histone methylation changes in fetal germ cells in such a way that it can alter later development and/or pass on this epigenetic change to the next generation. As the foregoing discussion makes clear, such effects are certainly feasible from the perspectives of exposure (diet) and opportunity (germ cell epigenetic remodeling periods), but undertaking meaningful studies in humans is plagued with complexities, whether of the diet itself or of the numerous confounding factors (genetic, lifestyle, own development) that are likely to obstruct interpretation.

\section{Future prospects and concluding remarks}

If one accepts the premise that reproduction is our reason for being, a reasonable following conclusion is that we have been designed (or have been shaped during evolution) with this one purpose in mind; thus, the reproductive process is the pivot for the rest of our physiology. For those involved in non-reproductive biomedical research, this simple chain of logic will likely be alien and perhaps offensive, but in my opinion the evidence to support this notion is overwhelming. Only when one begins to view the world via this reproductive prism, can you gain a proper perspective, and then to ask the correct questions or to interpret data with the reproductive process at the forefront of your mind. My hope is that this brief overview will encourage others to think in the way that I have outlined and thus help to elevate 'reproductive biology' back onto the pedestal from which it has been dislodged. This I consider to be the easy task. The more difficult task is to persuade readers that the growing evidence for fetal programming and for inter-generational effects of diet may be 'reproductively purposeful', that it is evidence for rapid adaptive (epigenetic) mechanisms to better fit the future offspring to its nutritional environment so as to give it a reproductive advantage. I hope that the reader will agree with me that, at least at the descriptive level, there is abundant supporting evidence for this hypothesis, including in humans. However, whether the evidence that I have presented is actually indicative of cause and effect with a reproductive purpose requires numerous assumptions; and of course, assumptions are ultimately the ruin of most hypotheses.
The key issue in my opinion is whether the epigenetic changes induced in offspring by paternal diet are intentionally adaptive (for the offspring) or are simply the incidental downstream consequence of a change of paternal diet or metabolism. The latter presumes that nature is not so clever (almost a 'sitting duck'), whereas the former interpretation (my hypothesis) presumes that nature is ingenious. But how do we decide which is correct? For the moment, I consider that this dilemma cannot be resolved evidentially, because we lack any indisputable complete chain of evidence that connects a specific change in paternal diet to a specific epigenetic change(s), which can be shown to be transmitted to the next generation and to specifically cause biological changes in the offspring that are specific to the original dietary change in the father. Obtaining such information is enormously challenging, not least because the available evidence suggests that, at least for paternally mediated effects, dietary or experimentally induced changes in the father's sperm epigenome (e.g. miRNA profile, DNA methylome) are not recapitulated in the offspring or grand-offspring despite the fact that phenotypic changes are evident in these offspring as a result of the paternal dietary insult (Fullston et al. 2013, 2016, Siklenka et al. 2015, Chambers et al. 2016). Dissecting out cause and effect in such inter-generational studies, and designing the appropriate controls at each step, is a Herculean task, that is further limited by our present poor understanding of epigenetic processes, their regulation and integration. We can be certain that this understanding will grow exponentially and hopefully this will facilitate a more targeted research approach to 'the chain of effect' issue just outlined. More studies along the lines of investigating dietary effects in real-world situations, such as those conducted in rural Gambian women as discussed earlier (Dominguez-Salas et al. 2013, 2014, Silver et al. 2015), is the most obvious way to make progress in this area.

An ever-present issue, and a big one, is the extent to which the mouse experimental inter-generational studies can be translated to us humans - thus, even if the hypothesis is correct, how big an influence is, for example, paternal diet on a father's offspring (Box 2)? If the effects are small, why should we bother? This leads to my biggest reservation, which is whether anyone will be bothered to even evaluate this hypothesis in other words to care whether or not reproduction has an intergenerational adaptive influence in our lives that extends far beyond the simple established transfer of DNA from parents to child. In this regard, the Gambian studies discussed earlier could also lead the way, if researchers can be motivated to investigate if seasonal dietary changes in mothers that are associated with DNA methylation changes in offspring, are also associated with reproductive changes in offspring. Other than this, I foresee that the focus will be on how diseases in our children are caused - and if aspects of paternal (or maternal) diet are proven to cause disease 
in our children, this will be the trigger to understand the epigenetic mechanisms involved. Whether or not this has an underlying reproductive purpose is a question that is rather unlikely to be asked, and in science, we all know that one only gets answers when one asks the right question. Hence, why I am posing this question now via this review. In doing so, my hope is that it will stimulate young researchers to see the truly big picture and to seek such an answer. If reproduction really is our biological reason for being, and if nature is as ingenious as the evidence all around us indicates it is, then framing our questions with this in mind will increase the chances of researchers asking the right questions. Whether this will prove the hypothesis right or wrong does not matter, what matters is to get an answer.

\section{Declaration of interest}

The author declares that there is no conflict of interest that could be perceived as prejudicing the impartiality of this review.

\section{Funding}

R M S was supported by grant G33253 from the UK Medical Research Council; the MRC Centre for Reproductive Health is funded by MRC Centre grant MR/N022556/1.

\section{References}

Aarabi M, San Gabriel MC, Chan D, Behan NA, Caron M, Pastinen T, Bourque G, MacFarlane AJ, Zini A \& Trasler J 2015 High-dose folic acid supplementation alters the human sperm methylome and is influenced by the MTHFR C677T polymorphism. Human Molecular Genetics 24 6301-6313. (https://doi.org/10.1093/hmg/ddv338)

Abe M, Tsai SY, Jin S-G, Pfifer GP \& Szabo PE 2011 Sex-specific dynamics of global chromatin changes in fetal mouse germ cells. PLOS ONE 6 e23848. (https://doi.org/10.1371/journal.pone.0023848)

Aiken CE, Tarry-Adkins JL \& Ozanne SE 2015 Transgenerational developmental programming of ovarian reserve. Scientific Reports $\mathbf{5}$ 16175. (https://doi.org/10.1038/srep16175)

Aiken CE, Tarry-Adkins JL \& Ozanne SE 2016a Transgenerational effects of maternal diet on metabolic and reproductive ageing. Mammalian Genome 27 430-439. (https://doi.org/10.1007/s00335-016-9631-1)

Aiken CE, Tarry-Adkins JL, Penfold NC, Dearden L \& Ozanne SE $2016 \mathrm{~b}$ Decreased ovarian reserve, dysregulation of mitochondrial biogenesis, and increased lipid peroxidation in female mouse offspring exposed to an obesogenic maternal diet. FASEB Journal 30 1548-1556. (https://doi. org/10.1096/fj.15-280800)

Alexander BT, Dasinger JH \& Intapad S 2015 Fetal programming and cardiovascular pathology. Comprehensive Physiology 5 997-1025. (https://doi.org/10.1093/ije/dyt133)

Anukulkitch C, Rao A, Dunshea FR, Blache D, Lincoln GA \& Clarke IJ 2007 Influence of photoperiod and gonadal status on food intake, adiposity, and gene expression of hypothalamic appetite regulators in a seasonal mammal. American Journal of Regulatory and Integrated Comparative Physiology 292 R242-R252. (https://doi.org/10.1152/ ajpregu.00417.2006)

Anway MD, Cupp AS, Uzumcu M \& Skinner MK 2005 Epigenetic transgenerational actions of endocrine disruptors and male fertility. Science 308 1466-1469. (https://doi.org/10.1126/science.1108190)

Bale TL 2014 Lifetime stress experience: transgenerational epigenetics and germ cell programming. Dialogues in Clinical Neuroscience 16 297-305.

Banik A, Kandilya D, Ramya S, Stunkel W, Chong YS \& Dheen ST 2017 Maternal factors that induce epiegentci changes contribute to neurological disorders in offspring. Genes 8 150. (https://doi. org/10.1210/en.2010-1093)

Barres R \& Zierath JR 2016 The role of diet and exercise in the transgenerational epigenetic landscape of T2DM. Nature Reviews Endocrinology 12 441-451. (https://doi.org/10.1038/nrendo.2016.87)

Biermann K \& Steger K 2007 Epigenetics in male germ cells. Journal of Andrology 28 466-480. (https://doi.org/10.2164/jandrol.106.002048)

Binder NK, Sheedy JR, Hannan NJ \& Gardner DK 2015 Male obesity is associated with changed spermatozoa Cox4i1 mRNA level and altered seminal vesicle fluid composition in a mouse model. Molecular Human Reproduction 21 424-434. (https://doi.org/10.1093/molehr/gav010)

Birbilis M, Moschonis G, Mougios V, Manios Y \& Healthy Growth Study group 2013 Obesity in adolescence is associated with perinatal risk factors, parental BMI and sociodemographic characteristics. European Journal of Clinical Nutrition 67 115-121. (https://doi.org/10.1038/ ejcn.2012.176)

Biro FM \& Kiess W 2016 Contemporary trends in onset and completion of puberty, gain in height and adiposity. Endocrine Development 29 122-133. (https://doi.org/10.1159/000438881)

Brykczynska U, Hisano M, Erkek S, Ramos L, Oakeley EJ, Roloff TC, Beisel C, Schubeler D, Stadler MB \& Peters AHF 2010 Repressive and active histone methylation mark distinct promoters in human and mouse spermatozoa. Nature Structural and Molecular Biology 17 679-687. (https://doi.org/10.1038/nsmb.1821)

Canovas S, Campos R, Aquilar E \& Cibelli JB 2017 Progress towards human primordial germ cell specification in vitro. Molecular Human Reproduction 23 4-15. (https://doi.org/10.1093/molehr/gaw069)

Carone BR, Fauquier L, Habib N, Shea JM, Hart CE, Li R, Brock C, Li C, Zamore PD, Meissner A et al. 2010 Paternally-induced transgenerational environmental reprogramming of metabolic gene expression in mammals. Cel/143 1084-1096. (https://doi.org/10.1210/en.2013-1013)

Chambers TJG, Morgan MD, Heger AH, Sharpe RM \& Drake AJ 2016 High-fat diet disrupts metabolism in two generations of rats in a parentof-origin specific manner. Scientific Reports 6 31857. (https://doi. org/10.1038/srep31857)

Cheong JN, Wlodek ME, Moritz KM \& Cuffe JS 2016 Programming of maternal and offspring disease: impact of growth restriction, fetal sex and transmission across generations. Journal of Physiology 594 4727-4740. (https://doi.org/10.1113/JP271745)

Clarke IJ, Scott CJ, Rao A, Pompolo S \& Barker-Gibb ML 2000 Seasonal changes in the expression of neuropeptide $\mathrm{Y}$ and pro-opiomelanocortin mRNA in the arcuate nucleus of the ovariectomized ewe: relationship to the seasonal appetite and breeding cycles. Journal of Neuroendocrinology 12 1105-1111. (https://doi.org/10.1046/j.1365-2826.2000.00570.x)

Comninos AN, Wall MB, Demetrious L, Shah AJ, Clarke SA, Narayanaswamy S, Nesbitt A, Izzi-Engbeaya C, Prague JK, Abbara A et al. 2017 Kisspeptin modulates sexual and emotional brain processing in humans. Journal of Clinical Investigation 127 709-719. (https://doi. org/10.1172/JCl89519)

Cummings DR 2014 Seasonality updated in 28 European/Mediterranean countries: a continuing enigma. American Journal of Human Biology 26 424-426. (https://doi.org/10.1002/ajhb.22534)

Czeizel AE, Dudas I, Paput L \& Banhidy F 2011 Prevention of neural-tube defects with periconceptual folic acid, methylfolate, or multivitamins? Annals of Nutrition and Metabolism 58 263-271. (https://doi. org/10.1159/000330776)

Daxinger L \& Whitelaw E 2012 Understanding transgenerational epigenetic inheritance vis the gametes in mammals. Nature Reviews Genetics 13 153-162. (https://doi.org/10.1038/nrg3188)

Dean A \& Sharpe RM 2013 Anogenital distance or digit ratio as measures of fetal androgen exposure: relationship to male reproductive development and its disorders. Journal of Clinical Endocrinology and Metabolism 98 2230-2238. (https://doi.org/10.1210/jc.2012-4057)

Dean A, van den Driesche S, Wang Y, McKinnell C, Macpherson S, Eddie SL, Kinnell H, Hurtado-Gonzalez P, Chambers TJ, Stevenson K et al. 2016 Analgesic exposure in pregnant rats affects fetal germ cell development with inter-generational reproductive consequences. Scientific Reports 6 19789. (https://doi.org/10.1038/srep19789)

Denisenko O, Lucas ES, Sun C, Watkins AJ, Mar D, Bomsztyk K \& Fleming TP 2016 Regulation of ribosomal RNA expression across the lifespan is finetuned by maternal diet before implantation. Biochimica et Biophysica Acta 1859 906-913. (https://doi.org/10.1016/j.bbagrm.2016.04.001) 
Desai M, Jellyman JK \& Ross MG 2015 Epigenomics, gestational programming and risk of metabolic syndrome. International Journal of Obesity 39 633-641. (https://doi.org/10.1038/ijo.2015.13)

Dimri M, Bommi PV, Sahasrabuddhe AA, Khandekar JD \& Dimri GP 2010 Dietary omega-3 polyunsaturated fatty acids suppress expression of EZH2 in breast cancer cells. Carcinogenesis 31 489-495. (https://doi. org/10.1093/carcin/bgp305)

Dominguez-Salas P, Moore SE, Cole D, da Costa KA, Cox SE, Dyer RA, Fulford AJ, Innis SM, Waterland RA, Zeisel SH et al. 2013 DNA methylation potential: dietary intake and blood concentrations of onecarbon metabolites and cofactors in rural African women. American Journal of Clinical Nutrition 97 1217-1227. (https://doi.org/10.3945/ ajcn.112.048462)

Dominguez-Salas P, Moore SE, Baker MS, Bergen AW, Cox SE, Dyer RA, Fulford AJ, Guan Y, Laritsky E, Silver MJ et al. 2014 Maternal nutrition at conception modulates DNA methylation of human metastable epialleles. Nature Communications 5 3746. (https://doi.org/10.1038/ncomms4746)

Donkin I, Versteyhe S, Ingerslev LR, Qian K, Mechta M, Nordkap L, Mortensen B, Appel EVR, Jorgensen N, Kristiansen VB et al. 2015 Obesity and bariatric surgery drive epigenetic variation of spermatozoa in humans. Cell Metabolism 23 369-378. (https://doi.org/10.1016/j. cmet.2015.11.004)

Drake AJ, O'Shaughnessy PJ, Bhattacharya S, Monteiro A, Kerrigan D, Goetz S, Raab A, Rhind SM, Sinclair KD, Meharg AA et al. 2015 In utero exposure to cigarette chemicals induces sex-specific disruption of one-carbon metabolism and DNA methylation in the human fetal liver. BMC Medicine 13 18. (https://doi.org/10.1186/s12916-014-0251-x)

Ebisch IMW, Thomas CMG, Peters WHM, Braat DDM \& SteegersTheunissen RPM 2007 The importance of folate, zinc and antioxidants in the pathogenesis and prevention of subfertility. Human Reproduction Update 13 163-174. (https://doi.org/10.1093/humupd/dml054)

Eckert JJ, Porter R, Watkins AJ, Burt E, Brooks S, Leese HJ, Humpherson PG, Cameron IT \& Fleming TP 2012 Metabolic induction and early responses of mouse blastocyst developmental programming following maternal low protein diet affecting life-long health. PLOS ONE 7 e52791. (https:// doi.org/10.1371/journal.pone.0052791)

Erkek S, Hisano M, Liang C-Y, Gill M, Murr R, Dieker J, Schubeler D, van der Vlag J, Stadler MB \& Peters AHF 2012 Molecular determinants of nucleosome retention at CpG-rich sequences in mouse spermatozoa. Nature Structural and Molecular Biology 20 868-875. (https://doi. org/10.1038/nsmb.2599)

Fisher ML, Adhikary G, Grun D, Kaetzel DM \& Eckert RL 2016 The Ezh2 polycomb group protein drives an aggressive phenotype in melanoma cancer stem cells and is a target of diet derived sulforaphane. Molecular Carcinogenesis 55 2024-2036. (https://doi.org/10.1002/mc.22448)

Fleming TP, Velazquez MA, Eckert JJ, Lucas ES \& Watkins AJ 2012 Nutrition of females during the peri-conceptual period and effects on foetal programming and health of offspring. Animal Reproduction Science 130 193-197. (https://doi.org/10.1016/j.anireprosci.2012.01.015)

Fleming TP, Velazquez MA \& Eckert JJ 2015 Embryos, DOHaD and David Barker. Journal of Developmental Origins of Health and Disease 6 377-383. (https://doi.org/10.1017/S2040174415001105)

Fontana L, Adelaiye RM, Rastelli AL, Miles KM, Ciamporcero E, Longo VD, Nguyen H, Vessella R \& Pili R 2013 Dietary protein restriction inhibits tumor growth in human xenograft models. Oncotarget 4 2451-2461. (https://doi.org/10.18632/oncotarget.1586)

Fullston T, Palmer NO, Owens JA, Mitchell M, Bakos HW \& Lane M 2012 Diet induced paternal obesity in the absence of diabetes diminishes the reproductive health of two subsequent generations of mice. Human Reproduction 27 1391-400. (https://doi.org/10.1093/humrep/des030)

Fullston T, Ohlsson Teaguue EM, Palmer NO, DeBasio MJ, Mitchell M, Corbett M, Print CG, Owens JA \& Lane M 2013 Paternal obesity initiates metabolic disturbances in two generations of mice with incomplete penetrance to the F2 generation and alters the transcriptional profile of testis and sperm microRNA content. FASEB Journal 27 4226-4243. (https://doi.org/10.1096/fj.12-224048)

Fullston T, Ohlsson Teaguue EM, Print CG, Sandeman LY \& Lane M 2016 Sperm microRNA content is altered in a mouse model of male obesity, but the same suite of microRNAs are not altered in offspring's sperm. PLOS ONE 11 e0166076. (https://doi.org/10.1371/journal.pone.0166076)

Gavela-Perez T, Navarro P, Soriano-Guillen L \& Garces C 2016 High prepubertal leptin levels are associated with earlier menarcheal age.
Journal of Adolescent Health 59 177-181 (https://doi.org/10.1016/j. jadohealth.2016.03.042)

Gluckman PD \& Hanson MA 2006 Changing times: the evolution of puberty. Molecular and Cellular Endocrinology 254-255 26-31. (https:// doi.org/10.1016/j.mce.2006.04.005)

Grace KS \& Sinclair KD 2009 Assisted reproductive technology, epigenetics, and long-term health: a developmental time bomb ticking. Seminars in Reproductive Medicine 27 409-416. (https://doi. org/10.1055/s-0029-1237429)

Grandjean V, Fourre S, De Abreu DA, Derieppe MA, Remy JJ \& Rassoulzadegan M 2015 RNA-mediated paternal heredity of dietinduced obesity and metabolic disorders. Scientific Reports 518193. (https://doi.org/10.1038/srep18193)

Gueant J-L, Namour F, Gueant-Rodriguez R-M \& Daval J-L 2013 Folate and fetal programming: a play in epigenomics. Trends in Endocrinology and Metabolism 24 279-289. (https://doi.org/10.1016/j.tem.2013.01.010)

Guo H, Hu B, Yan L, Yong J, Wu Y, Gao Y, Guo F, Hou Y, Dong J et al. 2017 DNA methylation and chromatin accessibility profiling of mouse and human fetal germ cells. Cell Research 27 165-183. (https://doi. org/10.1038/cr.2016.128)

Hales CN \& Barker DJ 2012 Type 2 (non-insulin-dependent) diabetes mellitus: the thrifty phenotype hypothesis. International Journal of Epidemiology 42 1215-1222. (https://doi.org/10.1093/ije/dyt133)

Hammoud SS, Nix DA, Zhang H, Purwar J, Carrell DT \& Cairns BR 2009 Distinctive chromatin in human sperm packages genes for embryo development. Nature 460 473-478. (https://doi.org/10.1038/ nature08162)

Hayward AD \& Lummaa V 2013 Testing the evolutionary basis of the predictive adaptive response hypothesis in a preindustrial human population. Evolution, Medicine, and Public Health 2013 106-117. (https://doi.org/10.1093/emph/eot007)

Henningsen JB, Gauer F \& Simonneaux V 2016 RFRP neurons - the doorway to understanding seasonal reproduction in mammals. Frontiers in Endocrinology 7 36. (https://doi.org/10.3389/fendo.2016.00036)

Holm JB, Mazaud-Guittol S, Danneskold-Samsoe NB, Chalmey C, Jensen B, Norregard MM, Hansen CH, Styrishave B, Svingen T, Vinggaard AM et al. 2016 Intrauterine exposure to paracetamol and aniline impairs female reproductive development by reducing follicle reserves and fertility. Toxicological Science 150 178-189. (https://doi. org/10.1093/toxsci/kfv332)

Huypens P, Sass S, Wu M, Dyckhoff D, Tschop M, Theis F, Marschall S, Hrabe de Angelis M \& Beckers J 2016 Epigenetic germline inheritance of diet-induced obesity and insulin resistance. Nature Genetics $\mathbf{4 8}$ 497-499. (https://doi.org/10.1038/ng.3527)

Iqbal K, Tran DA, Li AX, Warden C, Bai AY, Singh P, Wu X, Pfeifer GP \& Szabo PE 2015 Deleterious effects of endocrine disruptors are corrected in the mammalian germline by epigenome reprogramming. Genome Biology 16 59. (https://doi.org/10.1186/s13059-015-0619-z)

Johnson AD \& Alberio R 2015 Primordial germ cells: the first lineage or the last cell standing? Development 142 2730-2739. (https://doi. org/10.1242/dev.113993)

Jorgensen N, Andersen A-G, Eustache F, Irvine DS, Suominen J, Petersen JH, Andersen AN, Auger J, Cawood EH, Horte A et al. 2001 Regional differences in semen quality in Europe. Human Reproduction 16 1012-1019. (https://doi.org/10.1093/humrep/16.5.1012)

Joubert BR, den Dekker HT, Felix JF, Bohlin J, Ligthart S, Beckett E, Tiemeier H, van Meurs JB, Uitterlinden AG, Hofman A et al. 2016 Maternal plasma folate impacts differential DNA methylation in an epigenome-wide meta-analysis of newborns. Nature Communications 7 10577. (https://doi.org/10.1038/ncomms10577).1038/ncomms10577

Kanwal R, Datt M, Liu X \& Gupta S 2016 Dietary flavones as dual inhibitors of DNA methyltransferases and histone methyltransferases. PLOS ONE 11 e0162956. (https://doi.org/10.1371/journal.pone.0162956)

Kaplowitz PB 2008 Link between body fat and the timing of puberty. Pediatrics 121 (Supplement 3) 208-217. (https://doi.org/10.1542/peds.2007-1813F)

King V, Dakin RS, Liu L, Hadoke PW, Walker BR, Seckl JR, Norman JE \& Drake AJ 2013 Maternal obesity has little effect on the immediate offspring but impacts on the next generation. Endocrinology 154 2514-2524. (https://doi.org/10.1210/en.2013-1013)

Kobayashi H, Sakurai T, Miura F, Imai M, Mochduki K, Yanagisawa E, Sakashita A, Wakai T, Suzuki Y, Ito T et al. 2013 High-resolution DNA methylome analysis of primordial germ cells identifies gender-specific 
reprogramming in mice. Genome Research 23 616-627. (https://doi. org/10.1101/gr.148023.112)

Krautkramer KA, Kreznar JH, Romano KA, Vivas El, Barrett-Wilt GA, Rabaglia ME, Keller MP, Attie AD, Rey FE \& Denu JM 2016 Dietmicrobiota interactions mediate global epigenetic programming in multiple host tissues. Molecular Cell 64 982-992. (https://doi. org/10.1016/j.molcel.2016.10.025)

Kuhnen P, Handke D, Waterland RA, Hennig BJ, Silver M, Fulford AJ, Dominguez-Salas P, Moore SE, Prentice AM, Spranger J et al. 2016 Interindividual variation in DNA methylation at a putative POMC metastable allele is associated with obesity. Cell Metabolism 24 502-509. (https://doi.org/10.1016/j.cmet.2016.08.001)

Lambrot R, Xu C, Saint-Phar S, Chountalos G, Cohen T, Paquet M, Suderman M, Hallett M \& Kimmins S 2013 Low paternal dietary folate alters the mouse sperm epigenome and is associated with negative pregnancy outcomes. Nature Communications 4 2889. (https://doi. org/10.1038/ncomms3889)

Leka-Emiri S, Chrousos GP \& Kanaka-Gantenbein C 2017 The mystery of puberty initiation: genetics and epigenetics of idiopathic central precocious puberty (ICPP). Journal of Endocrinological Investigation $\mathbf{4 0}$ 789-802. (https://doi.org/10.1242/dev.113993)

Lesch BJ, Dokshin GA, Young RA, McCarrey JR \& Page DC 2013 A set of genes critical to development is epigenetically poised in mouse germ cells from fetal stages through completion of meiosis. PNAS 110 16061-16066. (https://doi.org/10.1073/pnas.1315204110)

Linabery AM, Nahhas RW, Johnson W, Choh AC, Towne B, Odegaard AO, Czerwinski SA \& Demerath EW 2013 Stronger influence of maternal than paternal obesity on infant and early childhood BMI: the Fels longitudinal study. Pediatric Obesity 8 159-169. (https://doi.org/10.1111/j.20476310.2012.00100.x)

Lincoln GA, Rhind SM, Pompolo S \& Clarke IJ 2001 Hypothalamic control of photoperiod-induced cycles in food intake, body weight, and metabolic hormones in rams. American Journal of Physiology and Regulatory Integrative Comparative Physiology 281 R76-R90.

Liu Y, Upadhyaya B, Fardin-Kia AR, Juenemann RM \& Dey M 2016 Dietary resistant starch type 4-derived butyrate attenuates nuclear factorkappa-B1 through modulation of histone $\mathrm{H} 3$ trimethylation at lysine 27 . Food Functions 7 3772-3781. (https://doi.org/10.1039/c6fo00856a)

Ly L, Chan D, Arabi M, Landry M, Behan NA, MacFarlane AJ \& Trasler J 2017 Intergenerational impact of paternal lifetime exposures to both folic acid deficiency and supplementation on reproductive outcomes and imprinted gene methylation. Molecular Human Reproduction 23 461-477. (https://doi.org/10.1093/molehr/gax029)

Maffoni S, De Guiseppe R, Stanford FC \& Cena H 2017 Folate status in women of childbearing age with obesity: a review. Nutrition Research Reviews 7 1-7. (https://doi.org/10.1017/S0954422417000142)

Malpaux B, Migaud M, Tricoire H \& Chemineau P 2001 Biology of mammalian photoperiodism and the critical role of the pineal gland and melatonin. Journal of Biological Rhythms 16 336-347. (https://doi. org/10.1177/074873001129002051)

Martin-Gronet MS, Stocker CJ, Wargent ET, Cripps RL, Garfield AS, Jovanovic Z, D'Agostino G, Yeo GS, Cawthorne MA, Arch JR et al. 2016 5-HT2A and 5-HT2C receptors as hypothalamic targets of developmental programming in male rats. Disease Model Mechanisms 9 401-412. (https://doi.org/10.1242/dmm.023903)

Matkovic V, Ilich JZ, Skugor M, Badenhop NE, Goel P, Clairmont A, Klisovic D, Nahhas RW \& Landoll JD 1997 Leptin is inversely related to age at menarche in human females. Journal of Clinical Endocrinology and Metabolism 82 3239-3245. (https://doi.org/10.1210/jcem.82.10.4280)

McMillen C, MacLaughlin SM, Muhlhauster BS, Gentili S, Duffield JL \& Morrison JL 2008 Developmental origins of adult health and disease: the role of periconceptual and foetal nutrition. Basic and Clinical Pharmacology and Toxicology 102 82-89. (https://doi.org/10.1111/ j.1742-7843.2007.00188.x)

McPherson NO, Fullston T, Bakos HW, Setchell BP \& Lane M 2014 Obese father's metabolic state, adiposity, and reproductive capacity indicate sons' reproductive health. Fertility and Sterility 101 865-873. (https:// doi.org/10.1016/j.fertnstert.2013.12.007)

Musial B, Vaughan OR, Fernandez-Twinn DS, Ozanne SE, Fowden AL \& Sferruzzi-Perri AN 2017 A Western-style obesogenic diet alters maternal metabolic physiology with consequences for fetal nutrient acquisition in mice. Journal of Physiology 595 4875-4892. (https://doi.org/10.1113/ JP273684)

Ng SF, Lin RC, Laybutt DR, Barres R, Owens JA \& Morris MJ 2010 Chronic high-fat diet in fathers programs $\beta$-cell dysfunction in female rat offspring. Nature 467 963-966. (https://doi.org/10.1038/nature09491)

Ost A, Lempradi A, Casas E, Weigert M, Tiko T, Deniz M, Pantano L, Boenisch U, Itskov PM, Stoeckius M et al. 2014 Paternal diet defines offspring chromatin state and intergenerational obesity. Cell 159 1352-1364. (https://doi.org/10.1016/j.cell.2014.11.005)

Palmer NO, Bakos HW, Owens JA, Setchell BP \& Lane M 2011 Diet and exercise in an obese mouse fed a high-fat diet improve metabolic health and reverse perturbed sperm function. American Journal of Physiology: Endocrinology and Metabolism 302 E768-E780. (https://doi. org/10.1152/ajpendo.00401.2011)

Patro B, Liber A, Zalewski B, Poston L, Szajewska H, Koletzko B 2013 Maternal and paternal body mass index and offspring obesity: a systematic review. Annals of Nutrition and Metabolism 63 32-41. (https://doi.org/10.1159/000350313)

Portha B, Chavey A \& Movassat J 2011 Early-life origins of type 2 diabetes: fetal programming of the beta-cell mass. Experimental Diabetes Research 2011 105076. (https://doi.org/10.1155/2011/105076)

Prokopuk L, Stringer JM, Hogg K, Elgass KD \& Western PS 2017 PRC2 is required for extensive reorganization of $\mathrm{H} 3 \mathrm{~K} 27 \mathrm{me} 3$ during epigenetic reprogramming in mouse fetal germ cells. Epigenetics and Chromatin $\mathbf{1 0}$ 7. (https://doi.org/10.1186/s13072-017-0113-9)

Radford EJ, Ito M, Shi H, Corish JA, Yamazawa K, Isganaitis E, Seisenberger S, Hore TA, ReikW, ErkekSetal.2014 In uteroeffects. In utero undernourishment perturbs the adult sperm methylome and intergenerational metabolism. Science 3451255903 (https://doi.org/10.1126/science.1255903)

Reik W 2007 Stability and flexibility of epigenetic gene regulation in mammalian development. Nature $\mathbf{4 4 7}$ 425-432. (https://doi. org/10.1038/nature05918)

Reynolds CM, Gray C, Li M, Segovia SA \& Vickers MH 2015 Early life nutrition and energy balance disorders in offspring in later life. Nutrients 7 8090-8111. (https://doi.org/10.3390/nu7095384)

Rodriguez-Miguel C, Moral R, Escrich R, Vela E, Solanas M \& Escrich E 2015 The role of dietary extra virgin olive oil and corn oil on the alteration of epigenetic patterns in the rat DMBA-induced breast cancer model. PLOS ONE 10 e0138980. (https://doi.org/10.1371/journal.pone.0138980)

Rojansky N, Brzezinski A \& Schenker JG 1992 Seasonality in human reproduction: an update. Human Reproduction 7 735-745. (https://doi. org/10.1093/oxfordjournals.humrep.a137729)

Sasaki H \& Matsui Y 2008 Epigenetic events in mammalian germ-cell development: reprogramming and beyond. Nature Reviews Genetics 8 129-140. (https://doi.org/10.1038/nrg2295)

Seisenberger S, Andrews S, Krueger F, Arand J, Walter J, Santos F, Popp C, Thienpoint B, Dean W \& Reik W 2012 The dynamics of genome-wide DNA methylation reprogramming in mouse primordial germ cells. Molecular Cell 48 849-862. (https://doi.org/10.1016/j. molcel.2012.11.001)

Seki Y, Yamagi M, Yabuta Y, Sano M, Shigeta M, Matsui Y, Saga Y, Tachibana M, Shinkai Y \& Saitou M 2007 Cellular dynamics associated with the genome-wide epigenetic reprogramming in migrating primordial germ cells in mice. Development 134 2627-2638. (https:// doi.org/10.1242/dev.005611)

Shankar E, Kanwal R, Candamo M \& Gupta S 2016 Dietary phytochemicals as epigenetic modifiers in cancer: promise and challenges. Seminars in Cancer Biology 40-41 82-99. (https://doi.org/10.1016/j. semcancer.2016.04.002)

Sharma U, Conine CC, Shea JM, Boskovic A, Derr AG, Bing XY, Belleannee C, Kucukural A, Serra RW, Sun F et al. 2016 Biogenesis and function of tRNA fragments during sperm maturation and fertilization in mammals. Science 351 391-396. (https://doi.org/10.1126/science. aad6780)

Sharpe RM 2017 Environmental causes of testicular dysfunction. In Hypogonadism, Second Edition, pp 281-304. Eds SJ Winters \& IP Huhtaniemi. Springer International. (https://doi.org/10.1007/978-3-31953298-1_14)

Siklenka K, Erkek S, Godmann M, Lambrot R, McGraw S, Lafleur C, Cohen T, Xia J, Suderman M, Hallett M et al. 2015 Disruption of histone methylation in developing sperm impairs offspring health 
transgenerationally. Science 350 aab2006. (https://doi.org/10.1126/ science.aab2006)

Silver MJ, Kessler NJ, Hennig BJ, Dominguez-Salas P, Laritsky E, Baker MS, Coarfa C, Hernandez-Vargas H, Castelino JM, Routledge MN et al. 2015 Independent genomewide screens identify the tumor suppressor VTRNA2-1 as a human epiallele responsive to periconceptual environment. Genome Biology 16 118. (https://doi.org/10.1186/s13059015-0660-y)

Sinclair KD, Karamitri A \& Gardner DS 2010 Dietary regulation of developmental programming in ruminants: epigenetic modifications in the germline. Society of Reproduction and Fertility Supplements $\mathbf{6 7}$ 59-72.

Skakkebaek NE, Rajpert-De Meyts E, Buck Louis GM, Toppari J, Andersson AM, Eisenberg ML, Jensen TK, Jorgensen N, Swan $\mathrm{SH}_{\text {, }}$ Sapra KJ et al. 2016 Male reproductive disorders and fertility trends: influences of environment and genetic susceptibility. Physiological Reviews 96 55-97. (https://doi.org/10.1152/physrev.00017.2015)

Smith JT 2012 The role of kisspeptin and gonadotropin inhibitory hormone in the seasonal regulation of reproduction in sheep. Domestic Animal Endocrinology 43 75-84. (https://doi.org/10.1016/j. domaniend.2011.11.003)

Smith JT \& Clarke IJ 2010 Seasonal breeding as a neuroendocrine model for puberty in sheep. Molecular and Cellular Endocrinology 324 102-109. (https://doi.org/10.1016/j.mce.2010.03.007)

Sorensen K, Aksglaede L, Petersen JH \& Juul A 2010 Recent changes in pubertal timing in healthy Danish boys: associations with body mass index. Journal of Clinical Endocrinology and Metabolism 95 263-270. (https://doi.org/10.1210/jc.2009-1478)

Sorensen K, Mouritsen A, Aksglaede L, Hagen CP, Mogensen SS \& Juul A 2012 Recent secular trends in pubertal timing: implications for evaluation and diagnosis of precocious puberty. Hormone Research in Paediatrics 77 137-145. (https://doi.org/10.1159/000336325)

Steegers-Theunissen RPM, Twigt J, Pestinger V \& Sinclair KD 2013 The periconceptual period, reproduction and long-term health of offspring: the importance of one-carbon metabolism. Human Reproduction Update 19 640-655. (https://doi.org/10.1093/humupd/dmt041)

Stringer JM, Barrand S \& Western P 2013 Fine-tuning evolution: germ-line epigenetics and inheritance. Reproduction 146 R37-R48. (https://doi. org/10.1530/REP-12-0526)

Sun C, Deisenko O, Sheth B, Cox A, Lucas ES, Smyth NR \& Fleming TP 2015 Epigenetic regulation of histone modifications and Gata6 gene expression induced by maternal diet in mouse embryoid bodies in a model of developmental programming. BMC Developmental Biology 15 3. (https://doi.org/10.1186/s12861-015-0053-1)

Sunde A, Brison D, Dumoulin J, Harper J, Lundin K, Magli MC, Van den Abbeel E \& Veiga A 2016 Time to take human embryo culture seriously. Human Reproduction 31 2174-2182. (https://doi.org/10.1093/humrep/ dew157)

Swaab DF 2007 Sexual differentiation of the brain and behavior. Best Practice and Research Clinical Endocrinology and Metabolism 21 431-444. (https://doi.org/10.1016/j.beem.2007.04.003)

Swayne BG, Kawata A, Behan NA, Williams A, Wade MG, MacFarlane AJ \& Yauk CL 2012 Investigating the effects of dietary folic acid on sperm count, DNA damage and mutation in Balb/c mice. Mutation Research 737 1-7. (https://doi.org/10.1016/j.mrfmmm.2012.07.002)

Szyf M 2015 Nongenetic inheritance and transgenerational epigenetics. Trends in Molecular Medicine 21 134-144. (https://doi.org/10.1016/j. molmed.2014.12.004)

Tang WW, Dietmann S, Irie N, Leitch HG, Floros VL, Bradshaw CR, Hackett JA, Chinnery PF \& Surani MA 2015a A unique gene regulatory network resets the human germline epigenome for development. Cell 161 1453-1467. (https://doi.org/10.1016/j.cell.2015.04.053)

Tang WW, Kobyashi T, Irie N, Dietmann S \& Surani MA 2015b Specification and epigenetic programming of the human germ line. Nature Reviews Genetics 17 585-600. (https://doi.org/10.1038/nrg.2016.88)

Tran TQ, Lowman XH \& Kong M 2017 Molecular pathways: metabolic control of histone methylation and gene expression in cancer. Clinical Cancer Research 23 4004-4009. (https://doi.org/10.1158/1078-0432. CCR-16-2506)

van den Driesche S, Kilcoyne KR, Wagner I, Rebourcet D, Boyle A, Mitchell R, McKinnell C, Macpherson S, Donat R, Shukla CJ et al. 2017 Experimentally induced testicular dysgenesis syndrome originates in the masculinization programming window. Journal of Clinical Investigation Insight 2 e91204. (https://doi.org/10.1172/jci.insight.91204)

Vickers MH, Clayton ZE, Yap C \& Sloboda DM 2011 Maternal fructose intake during pregnancy and lactation alters placental growth and leads to sex-specific changes in fetal and neonatal endocrine function. Endocrinology 152 1378-1387. (https://doi.org/10.1210/en.2010-1093)

Villamor E \& Jansen EC 2016 Nutritional determinants of the timing of puberty. Annual Reviews of Public Health 37 33-46. (https://doi. org/10.1146/annurev-publhealth-031914-122606)

Voigt P, Tee W-W \& Reinberg D 2013 A double take on bivalent promoters. Genes and Development 27 1318-1338. (https://doi.org/10.1101/ gad.219626.113

Wahab F, Shahab M \& Behr R 2015 The involvement of gonadotropin inhibitory hormone and kisspeptin in the metabolic regulation of reproduction. Journal of Endocrinology 225 R49-R66. (https://doi. org/10.1530/JOE-14-0688)

Watkins AJ, Ursell E, Panton R, Papenbrock T, Hollis L, Cunningham C, Wilkins A, Perry VH, Sheth B, Kwong WY et al. 2008 Adaptive responses by mouse early embryos to maternal diet protect fetal growth but predispose to adult onset disease. Biology of Reproduction $\mathbf{7 8}$ 299-306. (https://doi.org/10.1095/biolreprod.107.064220)

Wei Y, Schatten H \& Sun QY 2015 Environmental epigenetic inheritance through gametes and implications for human reproduction. Human Reproduction Update 21 194-208. (https://doi.org/10.1093/humupd/ dmu061)

Wermann H, Stoop H, Gillis AJM, Honecker F, van Gurp RJH, Ammerpohl O, Richter J, Oosterhuis JW, Bokemeyer C \& Looijenga LHJ 2010 Global DNA methylation in fetal human germ cell and germ cell tumours: association with differentiation and cisplatin resistance. Journal of Pathology 221 433-442. (https://doi.org/10.1002/path.2725)

Wong WY, Merkus HMW, Thomas CMG, Menkveld R, Zielhuis GA \& Steegers-Theunissen RPM 2002 Effects of folic acid and zinc sulfate on male factor subfertility: a double-blind, randomized, placebo-controlled trial. Fertility and Sterility $\mathbf{7 7}$ 494-498.

Xu J \& Sinclair KD 2015 One-carbon metabolism and epigenetic regulation of embryo development. Reproduction Fertility and Development $\mathbf{2 7}$ 667-676. (https://doi.org/10.1071/RD14377)

Zam W \& Khadour A 2017 Impact of phytochemicals and dietary patterns on epigenome and cancer. Nutrition and Cancer 69 184-200. (https:// doi.org/10.1080/01635581.2017.1263746)

Received 30 August 2017

First decision 17 November 2017

Revised manuscript received 8 December 2017

Accepted 21 December 2017 